\title{
EFFECT OF MENTHOL ON THE TRANSDERMAL PERMEATION OF ACECLOFENAC FROM MICROEMULSION FORMULATION
}

\author{
ABDUL BAQUEE AHMED1 ${ }^{*}$, GOURANGA DAS ${ }^{2}$ \\ *1Department of Pharmaceutics, Girijananda Chowdhury Institute of Pharmaceutical Science, Hathkhowapara, Azara, Guwahati, Assam \\ 781017, ${ }^{2}$ Girijananda Chowdhury Institute of Pharmaceutical Science, Hathkhowapara, Azara, Guwahati, Assam 781017 \\ Email: baquee1977@gmail.com
}

Received: 24 Nov 2018, Revised and Accepted: 09 Jan 2019

\begin{abstract}
Objective: The aim of this investigation was to enhance the transdermal permeation of aceclofenac (ACF) from microemulsion formulation using menthol as a natural permeation enhancer.

Methods: Microemulsion containing 2\% w/v of ACF was prepared by a titration method with different concentration of oil, surfactant and cosurfactant. The prepared microemulsion was evaluated for droplet size, viscosity, $\mathrm{pH}$ and in vitro skin permeation studies. Menthol at 3-8\% w/w was added to the selected microemulsion formulation and their effect on skin permeation was evaluated across rat epidermis using modified Keshary-Chien diffusion cell. The Fourier transform infrared spectroscopy (FT-IR) was performed to understand the regulation action of menthol in the skin permeability barrier.
\end{abstract}

Results: The average droplet size of the microemulsion was found to be $89.4 \pm 2.12$ to $175.2 \pm 3.10 \mathrm{~nm}$. The transdermal flux of the microemulsion containing $8 \% \mathrm{w} / \mathrm{w}$ menthol showed 2.9 fold increases in transdermal flux of ACF compared with the formulation without menthol. Result of FT-IR studies showed decrease in peak height of the symmetric and asymmetric $\mathrm{C}$ - $\mathrm{H}$ stretching vibrations may be because of the extraction of the stratum corneum (SC) lipids and the alteration of the skin permeability barrier.

Conclusion: This result suggests that menthol significantly enhanced the transdermal permeation of ACF and may be an effective natural penetration enhancer for transdermal delivery of the drug.

Keywords: Menthol, Microemulsion, Transdermal flux, Surfactant, Co-surfactant

(C) 2019 The Authors. Published by Innovare Academic Sciences Pvt Ltd. This is an open access article under the CC BY license (http://creativecommons.org/licenses/by/4.0/) DOI: http://dx.doi.org/10.22159/ijap.2019v11i2.30988

\section{INTRODUCTION}

Aceclofenac (ACF) (2-[(2, 6-dichlorophenyl) amine] phenylacetoxyacetic acid) is an orally effective non-steroidal anti-inflammatory drug (NSAID) of the phenylacetic acid group, which possesses remarkable antiinflammatory, analgesic, and antipyretic properties. It is used in the treatment of osteoarthritis and inflammatory disease of the joints [1-2]. The most widely cited side-effect of NSAIDs includes, gastrointestinal ulcer, accompanied by anemia due to the bleeding, which is also true for ACF. In order to avoid the gastric irritation, minimize the systemic toxicity and achieve a better therapeutic effect, one promising method is to administer the drug via skin [3-4].

Microemulsion typically consists of oil, surfactant, co-surfactant and an aqueous phase, which is transparent, thermodynamically stable and has a droplet size $<0.15 \mu \mathrm{m}$ and does not have the tendency to coalesce [5-6]. Microemulsion has several advantages such as enhanced drug solubility, good thermodynamic stability, ease of manufacturing and enhancement effect on transdermal delivery over conventional formulation [7, 8]. Recently, more attention has focused on microemulsions for transdermal delivery of drugs such as meloxicam [9], diclofenac diethylamine [10], triptolide [11].

On the other hand, one of the greatest obstacles in the transdermal route of drug delivery is the stratum corneum, since it provides a rate limiting step for drug absorption across the skin [12]. A popular technique to enhance the percutaneous absorption is the use of penetration enhancers that reversibly perturb the permeability barrier of the stratum corneum [13]. The most commonly used penetration enhancers include organic solvents, fatty acids and alcohols, terpenes and azone derivatives.

An ideal penetration enhancer should be pharmacologically inactive and nonirritant for the skin, potent and cosmetically acceptable [14]. Menthol, a naturally occurring terpenes compound (as showed in fig. 1) isolated from Mentha Piperita is free from toxic effects and has been approved as a penetration enhancer in the transdermal delivery of several hydrophilic and lipophilic drugs [15-17].<smiles>CC1CCC(C(C)C)C(O)C1</smiles>

Fig. 1: Molecular structure of menthol

However, the penetration-enhancing characteristic of menthol on the percutaneous absorption of ACF was not yet tested. In present study, o/w microemulsion containing ACF have been developed to achieve maximum skin permeation rate of the drug through excised rat epidermis using menthol as a natural penetration enhancer.

\section{MATERIALS AND METHODS}

Materials

ACF was a gift sample from IPCA Pharmaceutical Pvt. Ltd. (India), castor oil, soybean oil, olive oil, oleic acid, polyoxyethylene sorbitan monolaurate (tween 20), polyoxyethylene sorbitan monooleate (tween 80), sorbitan monooleate (span 80), ethanol, and isopropyl alcohol (IPA) were purchased from Merck Chemicals (Mumbai, India). Menthol (Aldrich Chemical, Germany), sodium bromide (Loba Chemie Pvt. Ltd., Mumbai, India) and chloroform (Thomas Baker Chemicals Pvt. Ltd., Mumbai, India) were procured and used in this investigation. Water was purified by double distillation in a glass apparatus. All other chemicals and solvents were of analytical grade.

\section{Methods}

Screening of oils, surfactants, and co-surfactants for microemulsion

The solubility of ACF was investigated in various oils (castor oil, olive oil, soybean oil, and oleic acid), surfactants (Tween 20, Tween 
80, Span 20) and co-surfactants (ethanol, IPA) to select a solvent system with good solubilizing capacity of ACF. An excess amount of ACF was added to $5 \mathrm{ml}$ of each of the solvent and shaken at $25^{\circ} \mathrm{C}$ for $72 \mathrm{~h}$ to attain equilibrium. The suspension was filtered through a $0.45 \mu \mathrm{m}$ membrane filter and the concentration of ACF in the filtrate was determined by UV spectrophotometer at $273 \mathrm{~nm}$.

\section{Construction of pseudo-ternary phase diagrams and formulation of ACF microemulsion}

The pseudo-ternary phase diagrams were constructed by installation of homogeneous liquid mixtures of oil, surfactant and cosurfactant with water at ambient temperature [18] at S/CoS ratio of $1: 1,2: 1,3: 1$ and 4:1 that resulted in large existent area of microemulsion containing ACF. The ratio of oil to mixture of S/CoS was varied from 9:1 to 1:9 and water was added drop by drop under continuous agitation. Usually with the addition of water to mixture of oils and $\mathrm{S} / \mathrm{CoS}$, the mixture become turbid at a certain point (beginning of phase inversion) and the turbid mixture again turned to clear indicating formation of $\mathrm{O} / \mathrm{W}$ microemulsion. Further, 2-8\% $\mathrm{w} / \mathrm{w}$ menthol was added to the selected formulations and the skin permeation rate of ACF was also evaluated across rat epidermis using Keshary-Chien diffusion cell.

\section{Characterization of microemulsion}

\section{Droplet size, $\mathrm{pH}$ and viscosity determination}

The average droplet size of the microemulsions were measured by dynamic light scattering (DLS) using a zetasizer nano-S90 (Malvern Instruments, England). Light scattering was monitored at $25^{\circ} \mathrm{C}$ at a $90^{\circ}$ angle. The $\mathrm{pH}$ of the formulations was determined by using a $\mathrm{pH}$ meter (TOSHNIWAL, Model CL 54) at $25 \pm 1{ }^{\circ} \mathrm{C}$. The viscosity of microemulsions was measured using a Brookfield rotational viscometer (LV2, Brookfield Inc., USA) equipped with the spindle no. 64 at $25^{\circ} \mathrm{C}$.

\section{In vitro skin permeation study}

The abdominal hair of Wistar male albino rats (obtained from M/S Ghosh Enterprises, Kolkata, India and maintained under controlled conditions of temperature as well as humidity), weighing 150-200 g, was shaved using an electric razor after sacrificing with excess chloroform inhalation. The abdominal skin was surgically removed and adhering subcutaneous fat was carefully cleaned. The epidermis was then separated from dermis by soaking the full thickness skin in $2 \mathrm{M}$ sodium bromide solution in water for 6-8 $\mathrm{h} \mathrm{[19].} \mathrm{The} \mathrm{epidermis}$ was thoroughly washed with water, dried at $25 \% \mathrm{RH}$, wrapped in aluminium foil and stored in freeze until further use. All experiments with animals were approved by the institutional animal ethics committee of Girijananda Chowdhury Institute of Pharmaceutical Science (GIPS/IAEC/M. ph/2014/3) India.

For in vitro permeation studies, skins were allowed to hydrate for 1 $\mathrm{h}$ before being mounted on the Keshary-Chien diffusion cell with the stratum corneum (SC) with effective surface area $1.54 \mathrm{~cm}^{2}$ facing the donor compartment. The receptor compartment was filled with 19.5 $\mathrm{ml}$ of $\mathrm{pH} 7.4$ phosphate buffer and its temperature was maintained at $37 \pm 0.5^{\circ} \mathrm{C} .1 \mathrm{ml}$ of microemulsion was applied on the SC side in the donor compartment and covered with aluminium foil to prevent drying out. $1 \mathrm{ml}$ of receptor medium was withdrawn every hour for $8 \mathrm{~h}$ after the application and replaced with an equal volume of fresh phosphate buffer $\mathrm{pH} 7.4$ equilibrated at $37 \pm 0.5^{\circ} \mathrm{C}$. The amount of drug permeated was determined spectrophotometrically at $273 \mathrm{~nm}$.

\section{Preparation of rat SC}

The rat epidermis was incubated for $4 \mathrm{hr}$ with $1 \%(\mathrm{w} / \mathrm{v})$ trypsin solution in phosphate buffer $\mathrm{pH} 7.4$ at $37^{\circ} \mathrm{C}$. The tissue was then smoothed out on a flat surface and the mushy epidermis was removed by rubbing with a moist, cotton-tipped applicator. The transparent SC so obtained was floated briefly on water, blotted dry, and used in the FT-IR studies [20-21].

\section{FT-IR studies of rat SC}

Earlier by Casal and Mantsch [22] have established that lipid extraction of SC can be observed with a decrease in the $\mathrm{C}-\mathrm{H}$ stretching absorbance intensity of FT-IR spectra of SC. In the present study rat SC was treated with 3-8\% menthol in 25:75 ratio of an ethanol-water co-solvent system for $24 \mathrm{~h}$. The treated SC samples were vacuum-dried $\left(650 \mathrm{~mm}\right.$ of $\mathrm{Hg}$ ) at $21 \pm 1^{\circ} \mathrm{C}$ for $2 \mathrm{~d}$ and stored in a desiccators to remove the traces of menthol and ethanol [23-24]. The completely dried samples of the SC were then subjected to FT-IR (Bruker Alpha, Germany) study and spectra were recorded in the frequency range of 400 to $4000 \mathrm{~cm}^{-1}$.

\section{RESULTS AND DISCUSSION}

\section{Screening of oils and surfactants}

The results of solubility studies of ACF showed variable solubility of ACF in oils, surfactant and co-surfactant. The solubility of ACF was found to be maximum in castor oil $(23.23 \pm 0.13 \mathrm{mg} / \mathrm{ml})$ followed by oleic acid $(4.20 \pm 2.00 \mathrm{mg} / \mathrm{ml})$, olive oil $(1.45 \pm 0.06 \mathrm{mg} / \mathrm{ml})$ and soy bean oil $(1.07 \pm 0.13 \mathrm{mg} / \mathrm{ml})$. Amongst the surfactants, tween 80 showed the maximum solubility $(65.27 \pm 2.77 \mathrm{mg} / \mathrm{ml})$ followed by tween $20(10.52 \pm 1.90 \mathrm{mg} / \mathrm{ml})$ and span $20(6.24 \pm 0.34 \mathrm{mg} / \mathrm{ml})$. Ethanol showed the highest solubility amongst the co-surfactants $(84.56 \pm 1.43 \mathrm{mg} / \mathrm{ml})$, followed by IPA $(48.60 \pm 3.69 \mathrm{mg} / \mathrm{ml})$. Based on solubility studies castor oil was chosen as oil phase, tween 80 and ethanol were chosen as surfactant and co-surfactant respectively to prepare microemulsion for ACF.

\section{Optimization of microemulsion formulation}

The phase diagram facilitated the determination of components concentration range for the existence of microemulsion. Fig. 2 showed the phase diagrams, constructed by ProSim ternary diagram software, version 1.0.3 to determine the optimum surfactant to cosurfactant ratio $(\mathrm{S} / \mathrm{CoS})$, for the formulation of $\mathrm{O} / \mathrm{W}$ microemulsion consisting of castor oil as oil phase, tween 80 as a surfactant, ethanol as co-surfactant, and water. The $\mathrm{S} / \mathrm{CoS}$ was varied as $1: 1,2: 1,3: 1$ and $4: 1$. With increases in $\mathrm{S} / \mathrm{CoS}$ ratio, the existence area of $\mathrm{O} / \mathrm{W}$ microemulsion becomes enlarged and reached maximum at $4: 1$ ratio. Based on this result, 4:1 ratio of $\mathrm{S} / \mathrm{CoS}$ was selected to formulate ACF microemulsion. The detailed compositions of all formulations were showed in table 1.

Table 1: Composition of ACF microemulsion

\begin{tabular}{|c|c|c|c|c|c|}
\hline \multirow{2}{*}{ F. code } & \multicolumn{5}{|l|}{ Components } \\
\hline & ACF $\% w / w$ & castor oil & S/CoS (tween 80/ethanol) & water & Menthol \% w/w \\
\hline ME1 & 2 & 5 & 25 & 68 & - \\
\hline ME2 & 2 & 5 & 50 & 43 & - \\
\hline ME3 & 2 & 5 & 75 & 18 & - \\
\hline ME4 & 2 & 10 & 25 & 63 & - \\
\hline ME5 & 2 & 10 & 50 & 38 & - \\
\hline ME6 & 2 & 10 & 75 & 13 & - \\
\hline ME7 & 2 & 15 & 25 & 58 & - \\
\hline ME8 & 2 & 15 & 50 & 33 & - \\
\hline ME9 & 2 & 15 & 75 & 8 & - \\
\hline ME10 & 2 & 10 & 25 & 63 & 3 \\
\hline ME11 & 2 & 10 & 25 & 63 & 6 \\
\hline ME12 & 2 & 10 & 25 & 63 & 8 \\
\hline
\end{tabular}




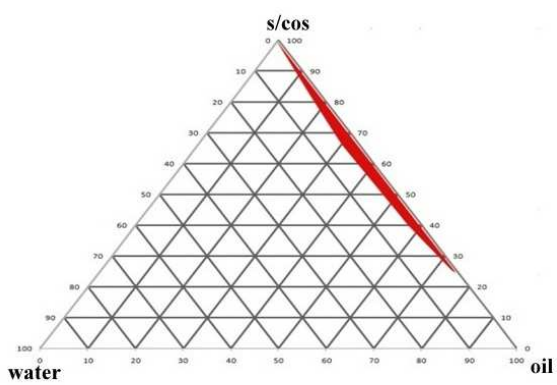

(a)

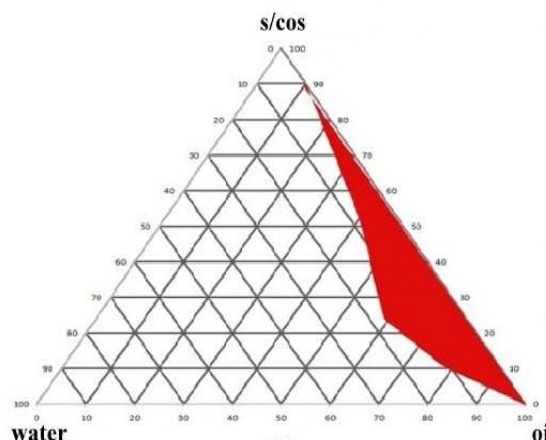

(c)

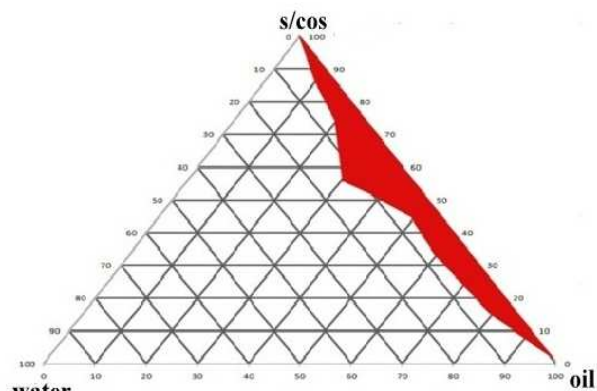

(b)

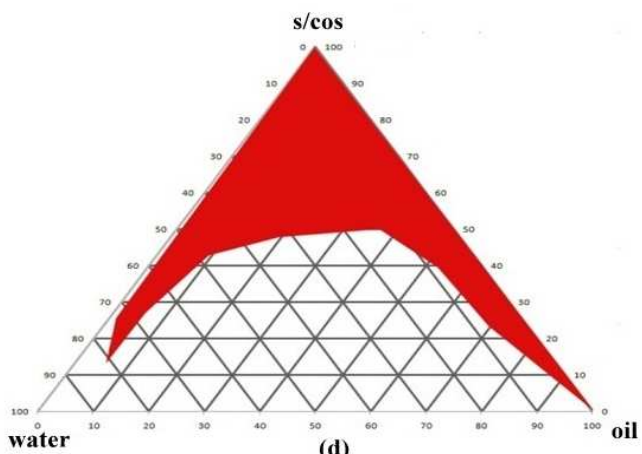

(d)

Fig. 2: Pseudo-ternary phase diagrams of microemulsion composed of castor oil, surfactant (tween 80), co-surfactant (ethanol) and water. (a) $S / \operatorname{CoS}, 1: 1$ (b) $S / \operatorname{CoS}, 2: 1$ (c) $S / \operatorname{CoS}, 3: 1$ (d) $S / \operatorname{CoS}, 4: 1$

\section{Physicochemical evaluation of microemulsion}

The results of the physical parameters of all formulations were presented in table 2. The average size of oil droplets of microemulsion formulations was found to be $89.4 \pm 2.12$ to
$175.2 \pm 3.10 \mathrm{~nm}$. The $\mathrm{pH}$ of the formulations was range $6.2 \pm 0.16$ $6.7 \pm 0.40$ and viscosity range $71-99 \mathrm{cP}$. The results of these study revealed that addition of $3-8 \% \mathrm{w} / \mathrm{w}$ menthol in the formulation did not significantly changes the physicochemical properties of the microemulsion.

Table 2: Physicochemical parameters of microemulsion formulations

\begin{tabular}{|c|c|c|c|c|}
\hline Formulations & $\mathbf{p H}^{*}$ & Particle size* (nm) & Polydispersity Index & Viscosity (cP) \\
\hline ME1 & $6.2 \pm 0.16$ & $105.3 \pm 1.05$ & 0.310 & 73 \\
\hline ME2 & $6.3 \pm 0.05$ & $151.2 \pm 2.15$ & 0.255 & 74 \\
\hline ME3 & $6.5 \pm 0.22$ & $101.6 \pm 1.25$ & 0.343 & 71 \\
\hline ME4 & $6.4 \pm 0.06$ & $170.7 \pm 1.03$ & 0.230 & 82 \\
\hline ME5 & $6.3 \pm 0.32$ & $102.6 \pm 3.05$ & 0.310 & 84 \\
\hline ME6 & $6.6 \pm 0.05$ & $93.5 \pm 1.50$ & 0.255 & 87 \\
\hline ME7 & $6.4 \pm 0.22$ & $166.1 \pm 2.52$ & 0.343 & 94 \\
\hline ME8 & $6.7 \pm 0.40$ & $152.3 \pm 1.15$ & 0.230 & 98 \\
\hline ME9 & $6.5 \pm 0.13$ & $89.4 \pm 2.12$ & 0.310 & 92 \\
\hline ME10 & $6.3 \pm 0.23$ & $157.4 \pm 3.05$ & 0.324 & 87 \\
\hline ME11 & $6.4 \pm 0.08$ & $166.1 \pm 1.09$ & 0.338 & 92 \\
\hline ME12 & $6.5 \pm 0.18$ & $175.2 \pm 3.10$ & 0.343 & 99 \\
\hline
\end{tabular}

$*($ mean $\pm S D, n=3)$

\section{In vitro skin permeation study}

The skin permeation profiles of all microemulsion formulations without menthol (ME1 to ME9) are presented in fig. 3. The cumulative amount of ACF permeated through excised rat skins was plotted as a function of time. The slope and intercept of the linear portion of the plot were derived by regression. The permeation rate at steady-state $\left(\mathrm{s}, \mu \mathrm{g} / \mathrm{cm}^{2} / \mathrm{h}\right)$ was calculated as the slope divided by the skin surface area. The intercept on the X-axis was taken as the lag time $\left(T_{\mathrm{L}}, \mathrm{h}\right)$. The permeation parameters calculated from the profiles are presented in table 3.

Amongst the formulations tested, Formulation ME4 showed the highest permeation profile rate of ACF after 8h permeation study. The cumulated amount of skin permeation of ACF from this formulation was found to be $1492.33 \pm 10.43 \mu \mathrm{g} / \mathrm{cm}^{2}$. The content of $\mathrm{S} / \mathrm{CoS}$ mixture in formulation affected the skin permeation of ACF significantly $(p<0.05)$. As the content of $S / \operatorname{CoS}$ mixture was increased from 25 to $75 \%$ in formulations (ME4 to ME6), the skin permeation rate of ACF was decreased $(1492.33 \pm 10.43$ to $1337.37 \pm 18.44 \mu \mathrm{g} / \mathrm{cm}^{2}$ ). The content of oil also played an important role in microemulsion formulation on the skin permeation of ACF as showed in the fig. 3. With decrease in oil content from $15 \%$ to $5 \%$ in formulations ME9, ME6, ME3 the skin permeation of ACF was increased and the cumulative drug permeated were found $1422.23 \pm 14.04, \quad 1337.33 \pm 18.44 \mu \mathrm{g} / \mathrm{cm}^{2}, \quad 1249.33 \pm 22.36, \mu \mathrm{g} / \mathrm{cm}^{2}$ respectively after $8 \mathrm{~h}$, while the content of surfactant and cosurfactant mixture $\mathrm{S} / \operatorname{CoS}(4: 1)$ was fixed at $75 \%$. This result suggested that, as the oil contents in the formulations decreased the water contents in the formulation increased which leads to hydrate skin and caused corneous cell to swell thus made drug channel wide, therefore with increasing amount of water content in the system the cumulative permeation amount was improved, this findings was supported with the previous study $[25,26]$. 
Table 3: Permeation parameters of ACF from different formulations across rat epidermis

\begin{tabular}{lll}
\hline Formulations & Permeation parameters (mean $\mathbf{S D}, \mathbf{n}=\mathbf{3})$ & \\
\cline { 2 - 3 } & $\mathbf{T}_{\mathbf{L}} \mathbf{( h )}$ & $\mathbf{J}_{\mathbf{s}}\left(\boldsymbol{\mu g} \mathbf{g} \mathbf{c m}^{2} / \mathbf{h}\right)$ \\
\hline ME1 & $0.86 \pm 0.23$ & $130.41 \pm 3.12$ \\
ME2 & $0.77 \pm 0.16$ & $144.16 \pm 5.04$ \\
ME3 & $0.68 \pm 0.31$ & $156.17 \pm 3.92$ \\
ME4 & $0.59 \pm 0.13$ & $186.54 \pm 6.20$ \\
ME5 & $0.73 \pm 0.24$ & $162.79 \pm 3.30$ \\
ME6 & $0.69 \pm 0.32$ & $167.16 \pm 5.32$ \\
ME7 & $0.81 \pm 0.22$ & $146.54 \pm 3.70$ \\
ME8 & $0.71 \pm 0.33$ & $151.54 \pm 4.23$ \\
ME9 & $0.64 \pm 0.62$ & $177.79 \pm 3.55$ \\
ME10 & $0.68 \pm 0.14$ & $311.54 \pm 14.80$ \\
ME11 & $0.64 \pm 0.23$ & $424.04 \pm 5.29$ \\
ME12 & $0.53 \pm 0.21$ & $540.79 \pm 15.05$ \\
\hline
\end{tabular}

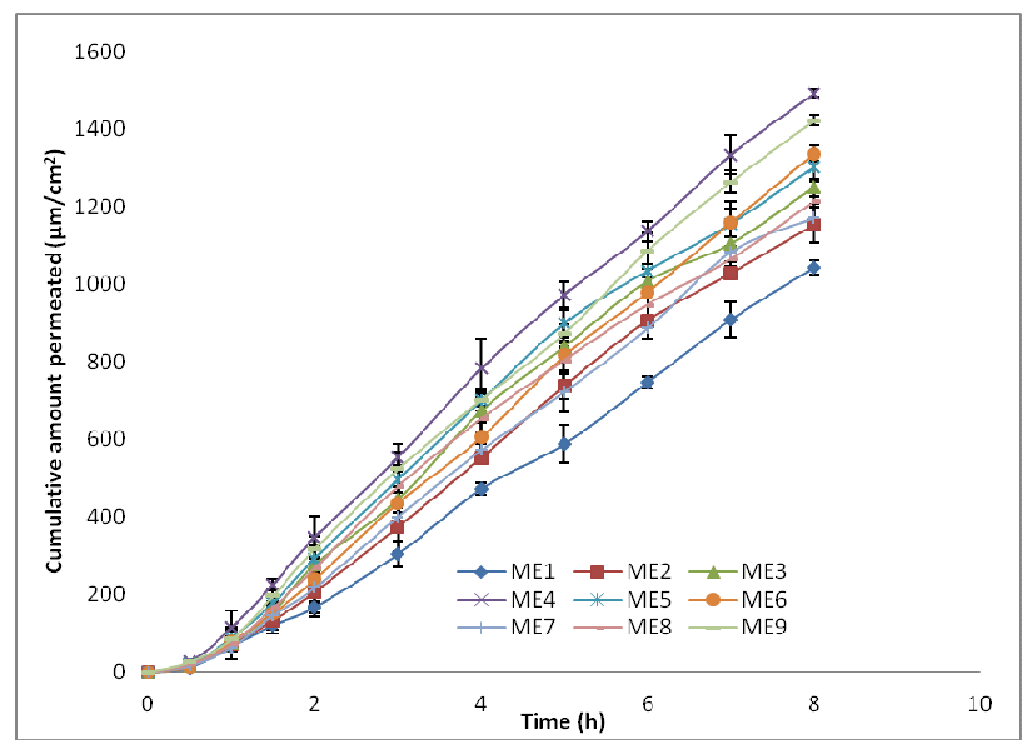

Fig. 3: Permeation profiles of ACF through rat epidermis from microemulsions. Bar represents mean \pm SD $(n=3)$

Further, to improve the permeation rate of ACF from microemulsion formulations menthol was added at $3 \% \mathrm{w} / \mathrm{w}, 6 \% \mathrm{w} / \mathrm{w}$ and $8 \% \mathrm{w} / \mathrm{w}$ in ME10, ME11 and ME12 formulations respectively. The obtained permeation profiles were showed in fig. 4 and the permeation parameters calculated from profiles were presented in table 3 . The permeation rate (transdermal flux) of ME10, ME11 and ME12 formulations were found to be $311.54 \pm 14.80,424.04 \pm 5.29$, $540.79 \pm 15.05 \mu \mathrm{g} / \mathrm{cm}^{2} / \mathrm{h}$ and a lag time $0.68 \pm 0.14,0.64 \pm 0.23$, and $0.53 \pm 0.21 \mathrm{~h}$ respectively, which revealed that formulation contained $8 \% \mathrm{w} / \mathrm{w}$ menthol (ME12) showed the most pronounced enhancing effect with 2.9 fold increased in the permeation rate of ACF as compared to control (ME4; without menthol).

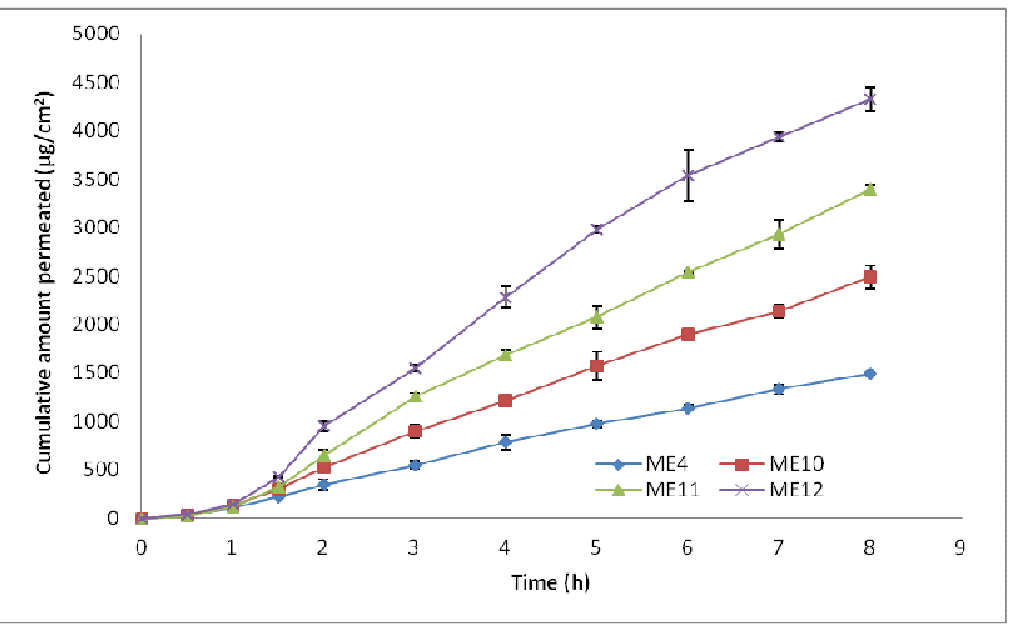

Fig. 4: Effect of menthol on transdermal permeation of ACF through rat epidermis from microemulsions. Bar represents mean \pm SD ( $n=3$ ) 


\section{FT-IR Spectroscopy of rat SC}

The FT-IR spectra of untreated rat SC showed characteristic absorption peaks (fig. 5A) at approximately $2852 \mathrm{~cm}^{-1}$ and $2921 \mathrm{~cm}^{-}$ 1 due to symmetric and asymmetric $\mathrm{C}-\mathrm{H}$ stretching vibrations of lipid components [27-28] and at approximately $1750-1550 \mathrm{~cm}^{-1}$ due to $\mathrm{C}=0$ stretching vibrations of an intracellular protein [29]. The FT-IR study showed that the treatment of SC with 3-8\% concentrations of menthol in 25:75 ratio of the ethanol-water solvent system did not produce a blue shift in the asymmetric and symmetric $\mathrm{C}-\mathrm{H}$ stretching peak positions. However, they all showed a significant decrease in absorbance intensities for both asymmetric and symmetric C-H stretching absorbance in comparison with the SC treated with 25:75 ration of the ethanol-water solvent system considered as control (table 4 and fig. 5B). 8\% menthol produced a greater decrease in peak heights for C-H stretching absorbance (asymmetric, $55.06 \pm 0.007 \%$ and symmetric $53.88 \pm 0.006 \%$ ) in comparison with the SC treated with $6 \%$ menthol (asymmetric, $48.41 \pm 0.008 \%$ and symmetric $40.29 \pm 0.007 \%$ ) and $3 \%$ menthol (asymmetric, $44.62 \pm 0.004 \%$ and symmetric $36.40 \pm 0.004 \%$ ). The decrease in peak height may be because of the extraction of the SC lipids and this result is in agreement with an earlier study reported by Goats and Knutson, 1994 [30]. It was also reported that terpenes increase the drug percutaneous permeation mainly by disrupting the intercellular packing of the SC lipids [31, 32]. Thus, the study suggests that extraction of the SC lipids by menthol at $3-8 \% \mathrm{w} / \mathrm{w}$ concentration was effective for enhancing the transdermal permeation of ACF from microemulsion drug reservoir.

Table 4: Peak height of asymmetric and symmetric $C-H$ stretching absorbance of rat $\mathrm{SC}($ mean $\pm \mathrm{SD}, \mathrm{n}=3$ )

\begin{tabular}{|c|c|c|c|c|}
\hline \multirow[t]{2}{*}{ Rat's stratum corneum treated with } & \multicolumn{2}{|c|}{ Asymmetric C-H stretching } & \multicolumn{2}{|c|}{ Symmetric C-H stretching } \\
\hline & Peak height & $\begin{array}{l}\text { \% Decrease in } \\
\text { peak height }^{\mathrm{a}}\end{array}$ & Peak height & $\begin{array}{l}\text { \% Decrease in } \\
\text { peak height }^{\text {a }}\end{array}$ \\
\hline Water & $3.21 \pm 0.02$ & $-\cdots$ & $2.18 \pm 0.04$ & $-\cdots--$ \\
\hline 25:75 (v/v) ethanol-water solvent system & $3.16 \pm 0.01$ & ----- & $2.06 \pm 0.01$ & 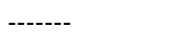 \\
\hline $3 \% \mathrm{w} / \mathrm{w}$ menthol in 25:75 (v/v) ethanol-water solvent system & $1.63 \pm 0.04$ & $48.41 \pm 0.008$ & $1.23 \pm 0.03$ & $40.29 \pm 0.007$ \\
\hline $6 \% \mathrm{w} / \mathrm{w}$ menthol in 25:75 (v/v) ethanol-water solvent system & $1.42 \pm 0.03$ & $55.06 \pm 0.007$ & $0.95 \pm 0.01$ & $53.88 \pm 0.006$ \\
\hline $8 \% \mathrm{w} / \mathrm{w}$ menthol in 25:75 (v/v) ethanol-water solvent system & $1.75 \pm 0.05$ & $44.62 \pm 0.004$ & $1.31 \pm 0.06$ & $36.40 \pm 0.004$ \\
\hline
\end{tabular}

a\%Decrease in peak height $=$ (peak height from ethanol-water treated SC-peak height from enhancer treated SC)/peak height from ethanol-water treated SC $\times 100[33]$.

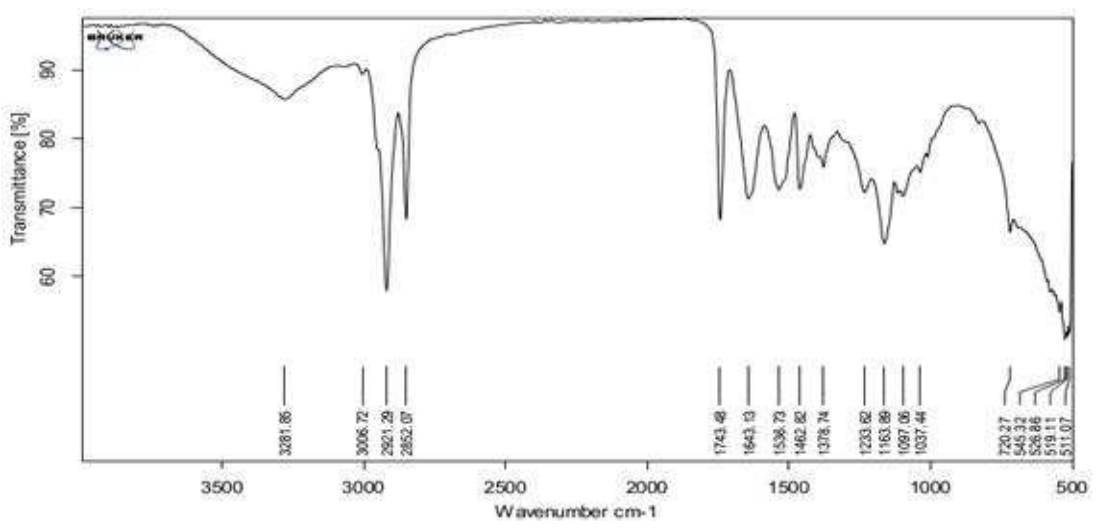

Fig. 5A: FT-IR spectra of rat SC

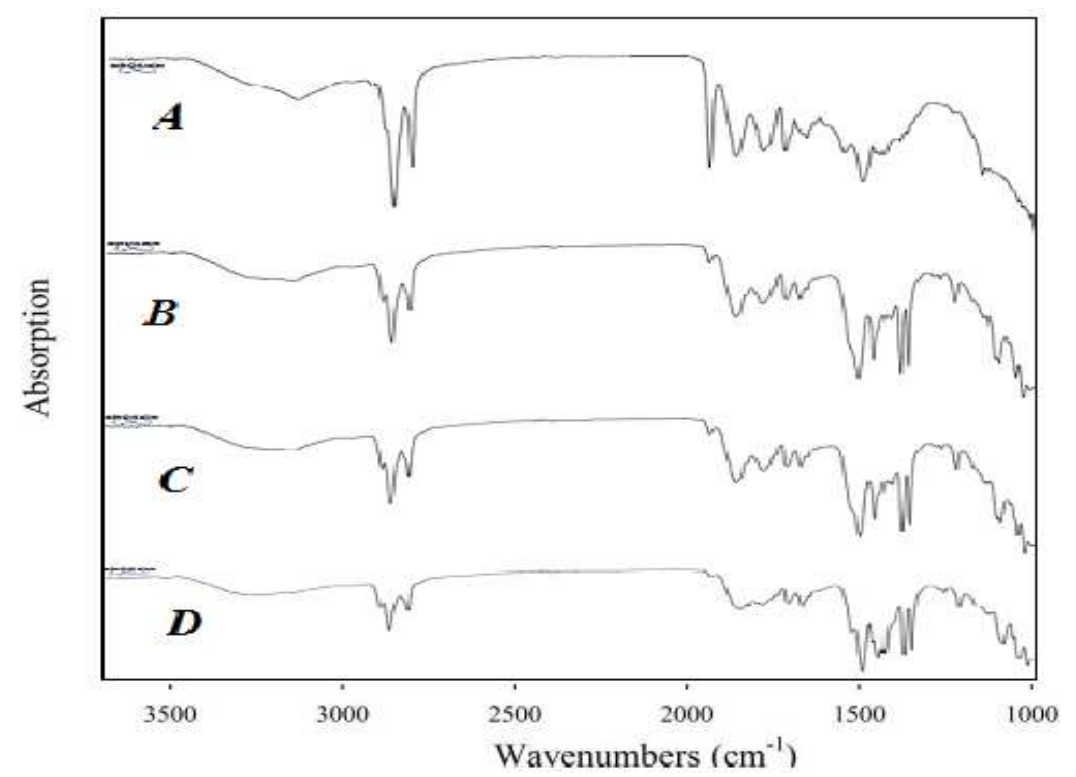

Fig. 5B: FT-IR spectra of rat SC treated with different concentration of menthol (A-without treatment, B-with $3 \%$ w/v menthol, C-with $6 \%$ w/v menthol, D-with $8 \%$ w/v menthol) 


\section{CONCLUSION}

In conclusion, an $\mathrm{O} / \mathrm{W}$ microemulsion containing $2 \% \mathrm{w} / \mathrm{v}$ of ACF was prepared successfully by a titration method with different concentration of oil, surfactant, and co-surfactant. The in vitro skin permeation studies showed that menthol could markedly enhance the transdermal permeation of ACF from microemulsion formulation. The average droplet size of the microemulsion was found to be $89.4 \pm 2.12$ to $175.2 \pm 3.10 \mathrm{~nm}$. The transdermal flux of the microemulsion containing $8 \% \mathrm{w} / \mathrm{w}$ menthol showed 2.9 fold increases in transdermal flux of ACF compared with the formulation without menthol. FT-IR studies revealed a decrease in peak height of the symmetric and asymmetric $\mathrm{C}-\mathrm{H}$ stretching vibrations may be because of the extraction of the SC lipids and the alteration of the skin permeability barrier. This result suggests that menthol may be an effective natural penetration enhancer for transdermal delivery of ACF.

\section{ACKNOWLEDGMENT}

The authors gratefully acknowledge IPCA Pharmaceutical Pvt. Ltd. India for providing gift sample of ACF.

\section{AUTHORS CONTRIBUTIONS}

All authors have contributed equally

\section{CONFLICTS OF INTERESTS}

The authors declare that there is no conflict of interest

\section{REFERENCES}

1. Brogden RN, Wiseman LR. Aceclofenac: a review of its pharmacodynamic properties and therapeutic potential in the treatment of rheumatic disorders and in pain management. Drugs 1996;52:113-24.

2. Jeeboi L, Boddu S. UV spectrophotometric method for simultaneous estimation of tramadol hydrochloride and aceclofenac in bulk and tablet dosage form. Int J Pharm Pharm Sci 2016;8:334-40.

3. Alvarez Larena A, Piniella JF, Carrasco E. Crystal structure and spectroscopic study of 2-[(2, 6-dichlorophenyl) amino] phenylacetoxyacetic acid (aceclofenac). J Chem Crystallography 1992;22:323-8.

4. McNeill SC, Potts RO, Francoeur ML. Local enhanced topical delivery (LETD) of drugs. Pharm Res 1992;9:1422-7.

5. Kreilgaard M. Influence of microemulsions on cutaneous drug delivery. Adv Drug Delivery Rev 2002;54(Suppl 1):S77-98.

6. Chaiyana W, Phongpradist R, Leelapornpisid P, Anuchapreeda S. Microemulsion-based hydrogel for topical delivery of indomethacin. Int J Pharm Pharm Sci 2015;7:213-9.

7. Lawrence MJ, Rees GD. Microemulsion-based media as novel drug delivery systems. Adv Drug Delivery Rev 2000;45:89-121.

8. Gasco MR. Microemulsions in the pharmaceutical field. In: Persperctives and Applications, Industrial Applications of Microemulsions. 1st ed. Marcel Dekker Inc.: New York; 1997; 45:97-122.

9. Zhong D, Mo F, Li S, Yuan Y. Investigation of microemulsion system for transdermal delivery of Meloxicam. Int J Pharm 2006;321:117-23.

10. Peltola S, Savolainen PS, Kiesvaara J, Suhonen TM, Urtti A. Microemulsions for topical delivery of estradiol. Int J Pharm 2003;254:99-107.

11. Chen HB, Chang XL, Weng T, Zhao XZ, Gao ZH, Yang YJ, et al. A study of microemulsion systems for transdermal delivery of triptolide. J Controlled Release 2004;98:427-36.

12. Wiechers JW. The barrier functions of the skin in relation to percutaneous absorption of drugs. Pharm Weekbl Sci 1989;11:185-98.

13. Krishnaiah YSR, Bhaskar P, Satyanarayana V. Penetrationenhancing effect of ethanol-water solvent system and an ethanolic solution of carvone on transdermal permeability of nimodipine from HPMC gel across rat abdominal skin. Pharm Dev Technol 2004;9:63-74.
14. Pfister W, Dean S, Hsieh S. Permeation enhancers compatible with transdermal drug delivery systems. I. Selection and formulation considerations. Pharm Technol 1990;8:132-40.

15. Gao S, Singh J. In vitro percutaneous absorption enhancement of lipophilic drug tamoxifen by terpenes. J Controlled Release 1998;51:193-9.

16. Hori M, Satoch H, Miabach HI, Guy RH. Enhancement effect of propranolol hydrochloride and diazepam skin absorption in vitro: effect of enhancer lipophilicity. J Pharm Sci 1991;80:32-5.

17. Okabe H, Takayama K, Ogura A, Nagai T. Effects of limonene and related compounds on the percutaneous absorption of indomethacin. Drug Des Delivery 1989;4:313-21.

18. Djordjevic L, Primorac M, Stupar M, Krajisnik D. Characterization of caprylocaproyl macrogolglycerides based microemulsion drug delivery vehicles for an amphiphilic drug. Int J Pharm 2004;271:11-9.

19. Thomas NS, Panchagnula R. Transdermal delivery of zidovudine: effect of vehicles on permeation across rat skin. Eur J Pharm Sci 2003;18:71-3.

20. Krishnaiah YSR, Satyanarayana V, Bhaskar P. Enhanced percutaneous permeability of nicardipine hydrochloride by carvone across the rat abdominal skin. Drug Dev Ind Pharm 2003;29:191-202.

21. Bhatia KS, Gao S, Singh J. Effect of penetration enhancers and iontophoresis on FT-IR spectroscopy and LHRH permeability through porcine skin. J Controlled Release 1997;47:81-9.

22. Casal HL, Mantsch HH. Polymeric phase behavior of phospolipid membranes studied by infrared spectroscopy. Biochim Biophys Acta 1984;779:381-401.

23. Krishnaiah YSR, Bhaskar P, Satyanarayana V. Penetrationenhancing effect of ethanol-water solvent system and an ethanolic solution of carvone on transdermal permeability of nimodipine from HPMC gel across rat abdominal skin. Pharm Dev Technol 2004;9:63-74.

24. Higuchi T. Physical analysis of percutaneous absorption processes from creams and ointments. J Soc Cosmet Chem 1960;11:85-97.

25. Thacharodi D, Rao KP. Transdermal absorption of nifedipine from microemulsions of lipophilic skin penetration enhancers. Int J Pharm 1994;111:235-41.

26. Alvarez Figueroa MJ, Blanco Mendez J. Transdermal delivery of methotrexate: iontophoretic delivery from hydrogels and passive delivery from microemulsions. Int $\mathrm{J}$ Pharm 2001;215:57-65.

27. Das MK, Ahmed AB. Skin permeation enhancement effects of ascorbic acid and triethyl citrate on rofecoxib. Malay J Pharm Sci 2008;6:69-86.

28. Krishnaiah YSR, Satyanarayan V, Karthikcyan RS. Penetration enhancing an effect of menthol on the percutaneous flux of nicardipin hydrochloride through excised rat epidermis from hydroxypropyl cellulose gels. Pharm Dev Technol 2002;7:305-15.

29. Babita K, Kumar V, Rana V, Jain S, Tiwary AK. Thermotropic and spectropic behavior of skin: Relationship with percutaneous permeation enhancement. Curr Drug Delivery 2006;3:95-113.

30. Goats CY, Knutson K. Enhanced permeation of polar compounds through human epidermis. I. Permeability and membrane structural changes in the presence of short chain alcohols. Biochem Biophys Acta 1994;1195:169-79.

31. Yamune MA, Williams AC, Barry BW. Terpenes penetration enhancers in propylene glycol/water co-solvent systems: effectiveness and mechanism of action. J Pharm Pharmacol 1995;47:978-89.

32. Cornwell P, Barry BW. Wide angle $\mathrm{x}$-ray diffraction of human stratum corneum effect of hydration and terpene enhancer treatment. J Pharm Pharmacol 1994;46:938-50.

33. Krishnaiah YSR, Bhaskar P, Satyanarayana V. Penetrationenhancing effect of ethanol-water solvent system and an ethanolic solution of carvone on transdermal permeability of nimodipine from HPMC gel across rat abdominal skin. Pharm Dev Technol 2004;9:63-74. 